Research Article

\title{
Characteristics of Newly Diagnosed Type 2 Diabetes in Chinese Older Adults: A National Prospective Cohort Study
}

\author{
Fang Lv $\mathbb{D}^{1},{ }^{1}$ Xiaoling Cai $\mathbb{D}^{1},{ }^{1}$ Dayi Hu, ${ }^{2}$ Changyu Pan, ${ }^{3}$ Danyi Zhang, ${ }^{4}$ Jie Xu, ${ }^{4}$ \\ and Linong Ji $\oplus^{1}$ \\ ${ }^{1}$ Department of Endocrinology and Metabolism, Peking University People's Hospital, Beijing, China \\ ${ }^{2}$ Department of Cardiology, Peking University People's Hospital, Beijing, China \\ ${ }^{3}$ Department of Endocrinology and Metabolism, Chinese People's Liberation Army General Hospital, Beijing, China \\ ${ }^{4}$ VitalStrategic Research Institute, Shanghai, China
}

Correspondence should be addressed to Xiaoling Cai; dr_junel@sina.com and Linong Ji; jiln@bjmu.edu.cn

Received 14 August 2019; Revised 7 October 2019; Accepted 15 October 2019; Published 15 November 2019

Academic Editor: Ulrike Rothe

Copyright (C) 2019 Fang Lv et al. This is an open access article distributed under the Creative Commons Attribution License, which permits unrestricted use, distribution, and reproduction in any medium, provided the original work is properly cited.

Aim. To investigate the metabolic profiles of newly diagnosed type 2 diabetes (NEW2D) in Chinese older adults ( $\geq 65$ years) and assess the proportion of patients who achieved the targeted goals of blood glucose, blood pressure, and blood lipid. Methods. NEW2D study was an observational, longitudinal, prospective cohort study involving patients who were diagnosed with type 2 diabetes (T2D) within the past 6 months and had a follow-up of 12 months. Participants were divided into younger NEW2D group (aged 20-65 years old) and older NEW2D group (aged $\geq 65$ years old) according to age of diabetes onset. The baseline metabolic profiles were compared and the proportion of patients achieving adequate control of blood glucose, blood pressure, and blood lipids in reference to target goals were assessed during treatment. Results. The older NEW2D $(n=1362)$ had a lower BMI, HbA1c\%, diastolic blood pressure, triglyceride, low-density lipoprotein cholesterol (LDL-C), and total cholesterol, higher systolic blood pressure, and high-density lipoprotein cholesterol levels at baseline. $47.8 \%, 66.7 \%$, and $39.4 \%$ reached the target of $\mathrm{HbAlc}<7.0 \%, \mathrm{BP}<140 / 90 \mathrm{mmHg}$, and $\mathrm{LDL}-\mathrm{C}<2.6 \mathrm{mmol} / \mathrm{L}$, respectively. After 12 months, the proportion achieving above three targets increased to $70.2 \%, 76.1 \%$, and $47.5 \%$, respectively. The proportions of patients achieving three combined therapeutic targets doubled from $13.5 \%$ to $26.7 \%$. Conclusion. The older NEW2D patients have special metabolic profiles compared with younger patients. The control of cardiovascular disease risk factors was suboptimal in older adults with type 2 diabetes.

\section{Introduction}

Diabetes, particularly type 2 diabetes (T2D), is becoming more prevalent in the general population, especially in older people [1]. In 2010, approximately 106 million people aged 60 years and older were living with T2D worldwide, and it is projected to increase to approximately 200 million by the year 2030 [2]. The China Non-communicable Disease Surveillance 2010 survey reported that the prevalence of diabetes in China was $22.5 \%$ and $23.5 \%$ in people aged $60-69$ years and $\geq 70$ years, respectively [3]. The estimated prevalence of newly diagnosed diabetes in older people was $14.2 \%$ to $15.5 \%$, making the development of therapeutic strategies targeted to this broad population of patients particularly challenging [3].

Diabetes mellitus, hypertension, and dyslipidemia, which often coexist in older people, have been shown to increase the risk of cardiovascular disease (CVD) and mortality $[4,5]$. However, only $29 \%$ patients aged $\geq 70$ years and $32.8 \%$ patients aged 60-69 years are taking diabetes medications among all patients with diabetes [3]. Moreover, only 38.9\% to $39.8 \%$ of patients in China treated for diabetes had adequate glycemic control [3]. Additionally, only a minority of adults with diabetes fully achieve recommended goals for glycemic control, blood pressure control, and management of dyslipidemia [6-10]. Evaluating the current control of 
glycemia, blood pressure, and lipid in older people with newly diagnosed type 2 diabetes (NEW2D) in China will promote a better management of risk factors of CVD in the future.

The older and younger people with newly diagnosed diabetes have unique metabolic characteristics. A cross-sectional survey of China National HbAlc Surveillance System (CNHSS) reported diabetes participants aged $>40$ years old had higher systolic blood pressure (SBP), higher lowdensity lipoprotein cholesterol (LDL-C), lower glycated hemoglobin ( $\mathrm{HbAlc}$ ), and similar BMI and triglyceride (TG) levels compared with early-onset diabetes participants (aged $\leq 40$ years) [11]. However, the China National Diabetes and Metabolic Disorders Study reported that late-onset diabetes NEW2D had higher SBP, cholesterol (CHO), LDL-C, and 2-hour post-prandial blood glucose compared with early-onset diabetes (aged 22-43 years) [12]. However, previous studies mainly focused on the metabolic profile in early-onset T2D, though age was not defined consistently in different studies. To our knowledge, metabolic characteristics has not previously been specifically investigated in Chinese older people aged 65 years with newly diagnosis of diabetes.

Therefore, the aim of our study was to evaluate the metabolic characteristics and control of glycemia, blood pressure, and lipid in the older NEW2D in a study of the China Cardiometabolic Registry for newly diagnosed type 2 diabetic patients (CCMR-NEW2D).

\section{Methods}

2.1. Study Design and Population. This study was a prospective, observational cohort study with 12-month follow-up $[13,14]$. From June 2012 to February 2014, patients from 81 hospitals (community hospitals (Tier 1), secondary/city level hospitals (Tier 2), and teaching or comprehensive central hospitals (Tier 3)) across six geographic regions of China (North, South, East, Southwest, Northeast, and Northwest) were recruited. Participants were enrolled at the department of endocrinology and internal medicine clinics. The inclusion criteria were as follows: (1) patients with 20 years' age or older; (2) patients with confirmed diagnosis of type 2 diabetes according to the World Health Organization criteria, within 6 months before screening; (3) patients who signed the consent form. The exclusion criteria were as follows: (1) patients who were pregnant or breastfeeding or planned to be pregnant within one year, (2) patients who were participating in another clinical trial, (3) patients who were not willing to or not able to return to the same hospital every 3 months for the follow-up visits after enrollment, and (4) patients without clear information regarding the medication used. CCMRNEW2D study was registered at http://www.clinicaltrials .gov (NCT01525693) on February 3rd, 2012.

Ethical approval was first obtained from the Ethic committees of Peking University People's Hospital and then was approved by all the participating hospitals. All patients provided written informed consent to participate in the study prior to being screened. The research methods of the study adhered to the Declaration on Helsinki and all research was reported in accordance with strengthening the reporting of observational studies in epidemiology (STROBE) Statement.

2.2. Study Procedures and Data Collection. The primary objectives of NEW2D study was to assess the evolution of treatment patterns for newly diagnosed T2D patients and the clinical outcomes during 12-month follow-up in realworld condition. The patients all received routine lifestyle suggestions as diet and exercise by the investigators and also medications prescribed by the investigators. These patients were required to return to the same physician for the follow-up visits at 3, 6, 9, and 12 months after the first visit. If the patient was lost at follow-up, a structured telephone interview would be performed by the investigator to realize the patient's condition.

Physical examinations and lab tests were performed at the baseline and follow-up visits, which were described previously $[13,14]$. The main clinical measurements including body mass index (BMI), waist circumference (WC), fasting plasma glucose (FPG), glycosylated hemoglobin (HbAlc), systolic and diastolic blood pressure (SBP and DBP), and total serum cholesterol (CHO, TG, LDL-C, and HDL-C). According to the Chinese Diabetes Guideline, the BMI cutoff values are categorized: $\mathrm{BMI}<18.5 \mathrm{~kg} / \mathrm{m}^{2}$ means thin, 18.5 $\leq \mathrm{BMI}<24 \mathrm{~kg} / \mathrm{m}^{2}$ means normal, $24 \leq \mathrm{BMI}<28 \mathrm{~kg} / \mathrm{m}^{2}$ means overweight, and $\mathrm{BMI} \geq 28 \mathrm{~kg} / \mathrm{m}^{2}$ means obese. Target goals of blood glucose, blood pressure, and blood lipids (3Bs) were as follows: $\mathrm{HbA1c}<7 \%, \mathrm{BP}<140 / 90 \mathrm{mmHg}$, and $\mathrm{LDL}-\mathrm{C}<2.6 \mathrm{mmol} / \mathrm{L}$. Another more strict treatment targets of $\mathrm{HbA1c}$ and $\mathrm{BP}$ were also set for this analysis: $\mathrm{HbA} 1 \mathrm{c}<6.5 \%$ and $\mathrm{BP}<140 / 80 \mathrm{mmHg}$. Another less strict treatment target of $\mathrm{HbA} 1 \mathrm{c}<7.5 \%$ was also set for this analysis. The overall proportion of patients reaching the target at baseline and follow-up were reported. For data collection and quality control, all the data were recorded in the approved case report form and entered into a web-based electronic data capture system designed by VitalStrategic Research Institute (VSRI) (Shanghai, China).

2.3. Statistical Analysis. Newly diagnosed diabetes participants were divided into two groups according to age: the younger NEW2D group (aged $<65$ years old) and the older NEW2D group (aged $\geq 65$ years old). Descriptive statistics were used to characterize the data in the study, including calculations of means and standard deviations. The frequency and percentages (based on the nonmissing sample size) of observed levels were reported for all categorical measures. Comparisons were statistically analyzed using one-way ANOVA and chi-squared tests. $p$ value $<0.05$ for the twotailed test was considered statistically significant. Statistical analyses were conducted using statistical analysis system (SAS) version 9.3 (SAS Institute, Cary, North Carolina, United States of America).

\section{Results}

Totally, 5770 patients from 79 hospitals, across six geographic regions of China, were included in this study. The average age of the patients was $55.7 \pm 12.6$ years. Among all 
the newly diagnosed diabetes participants, 1362 (23.6\%) participants were classified as older NEW2D.

3.1. Characteristics of Older NEW2D Participants. 38.6\%, $25.8 \%$, and $35.5 \%$ of the older NEW2D patients were from tier 1, tier 2, and tier 3 hospitals, respectively, of which the pattern distribution was different from that in younger diabetes group $(p<0.0001)$. Older NEW2D participants had higher proportion of females and less current smokers and drinking. The older participants were more likely to take regular exercises than their younger counterparts. The older participants had lower BMI, HbAlc\%, FPG, CHO, TG, LDL-C, and DBP and higher SBP and HDL-C levels compared with that of younger diabetes participants. In older NEW2D, 54.8\% patients had hypertension and $41.0 \%$ had dyslipidemia at baseline. 29.0\%, 15.2\%, and $25.8 \%$ had comorbid hypertension, dyslipidemia, or both. Baseline characteristics of younger and older newly diagnosed type 2 diabetes participants in China were shown in Table 1.

3.2. Glycemic, Blood Pressure, and Blood Lipid Control. The mean $\mathrm{HbA} 1 \mathrm{c}$ of the older NEW2D was $7.9 \pm 2.4 \%$ at baseline and decreased to $6.6 \pm 1.1 \%$ at 12 months. There was a significant linear downtrend of HbAlc over time (Figure 1(a)). Overall, $47.8 \%$ of the older NEW2D reached target glycemia of $\mathrm{HbA} 1 \mathrm{C}<7.0 \%$ at the baseline; $31.2 \%$ of patients reached the stricter target goal of $\mathrm{HbAlc}<6.5 \%$; $57.78 \%$ of patients reached the stricter target goal of $\mathrm{HbAlc}<7.5 \%$. By the end of 12 months follow-up, $70.2 \%$ people reached the recommended target goal of $\mathrm{HbAlc}<7.0 \%$ (Figure 2(a)).

The mean SBP in the older NEW2D was $133 \pm 15 \mathrm{mmHg}$ at the baseline and slightly decreased to $131 \pm 12 \mathrm{mmHg}$ at 12 months $(p<0.0001)$. Similarly, the mean DBP was $78 \pm 9$ $\mathrm{mmHg}$ at the baseline and decreased to $77 \pm 7 \mathrm{mmHg}$ at 12 months ( $p<0.001$ ) (Figure 1(b)). Overall, $67.7 \%$ of the older NEW2D reached the target blood pressure $(B P<140 / 90$ $\mathrm{mmHg}$ ) at baseline and $44.9 \%$ of them reached the stricter target goal of $B P<140 / 80 \mathrm{mmHg}$ (Figure 2(b)). At 12 months, the proportions of patients with adequate blood pressure control reached $76.1 \%$ using $<140 / 90 \mathrm{mmHg}$ criteria and $47 \%$ reached using $<140 / 80 \mathrm{mmHg}$ criteria.

The mean LDL-C was $2.8 \pm 0.9 \mathrm{mmol} / \mathrm{L}$ at the baseline and reduced to $2.7 \pm 0.9 \mathrm{mmol} / \mathrm{L}$ at 12 months $(p<0.0001)$. Overall, the proportion of the older NEW2D who achieved $\mathrm{LDL}-\mathrm{C}<2.6 \mathrm{mmol} / \mathrm{L}$ increased from $39.4 \%$ at baseline to $47.5 \%$ after 12 months $(p<0.0001)$ (Figure 2(c)). The mean levels of TC and TG decreased significantly after 12 months $(p<0.0001)$, and the mean level of HDL-C increased significantly after 12 months $(p<0.0001)$ (Figure $1(c)$ ). The proportions of patients, achieving the combined therapeutic targets of $\mathrm{HbAlc}<7.0 \%$, $\mathrm{BP}<140 / 90 \mathrm{mmHg}$, and $\mathrm{LDL}-\mathrm{C}<2.6$ $\mathrm{mmol} / \mathrm{L}$, doubled from $13.5 \%$ to $26.7 \%$ after 12 months of treatment $(p<0.0001)$ (Figure $2(\mathrm{~d}))$. And the proportion increased from $6.1 \%$ to $10.9 \%$ if the stricter control target of $\mathrm{HbAlc}<6.5 \%, \mathrm{BP}<140 / 80 \mathrm{mmHg}$ and $\mathrm{LDL}-\mathrm{C}<2.6$ $\mathrm{mmol} / \mathrm{L}(p<0.0001)$ was used.

3.3. Initial Treatment Patterns. At baseline, $42.7 \%$ of the older NEW2D were on diet and exercise alone and $1.0 \%$ of them had herbal medicine only. $41.9 \%$ of the patients took OHD only ( $26.9 \%$ with one OHA, $13.5 \%$ with two OHAs, and $1.5 \%$ with more than two OHAs, respectively). $5.9 \%$ participating patients were treated with OHA in combination with insulin; $8.5 \%$ were treated with insulin alone. Only $16.7 \%$ of the older patients received statin therapy.

\section{Discussion}

This large, multicentre, cross-sectional, hospital-based study in China revealed that $23.6 \%$ of patients were elderly among newly diagnosed patients with diabetes. The older NEW2D in China was characterized by lower BMI, HbAlc\%, FPG, CHO, TG, LDL-C, and DBP and higher SBP and HDL-C levels compared with younger patients aged less than 65 years old. The proportion of patients achieving adequate control of blood glucose, blood pressure, and blood lipids in reference to target goals improved during the 12-month follow-up, but still far from satisfactory.

It is well established that hyperglycemia, hypertension, and dyslipidemia are risk factors for microvascular diseases in T2D. Patients with T2D who had risk factor variables (such as elevated $\mathrm{HbA1c}$, elevated LDL-C, albuminuria, smoking, and elevated blood pressure) within the target ranges appeared to have little or no excess risk of death, myocardial infarction, or stroke, as compared with the general population [15]. However, only $26.7 \%$ of the older NEW2D achieved the combined therapeutic targets after 12-month follow-up. This finding represents a marked improvement from previous surveys conducted in 2010, in which only $5.6 \%$ of participants achieved all triple therapeutic goals for $\mathrm{HbA1c}, \mathrm{BP}$, and $\mathrm{CHO}$ [9]. Studies of different countries also observed that achieving adequate control of risk factors for cardiovascular disease in NEW2D patients was challenging and were still far from satisfactory, ranging from $1.4 \%$ to $24 \%$ according to different targets of blood glucose, blood pressure, and blood lipid set by different studies [6-10].

Evidence suggests that the benefit of intensive glucoselowering therapy is not uniform across all patients with T2D. There were few data specifically addressing optimal target $\mathrm{HbAlc}$ goals in older patients [16]. The widely accepted recommendation that all patients pursue $\mathrm{HbAlc}<7.0 \%$ is based largely on the results of the UK Prospective Diabetes Study, which actively excluded people aged $>65$ years [17]. The results of the Action to Control Cardiovascular Risk in Diabetes (ACCORD) trial suggest that intensive therapy in persons at high risk for CVD may increase the risk for both total and CVD mortality [18]. A 5-year retrospective cohort study in the UK reported that stable glycemic level in the middle range is associated with lower risk, and more stringent targets are associated with increased mortality in people with diabetes aged 70 years and older [19]. Therefore, goals for glycemic control in older T2D should be tailored to the individual, balancing the anticipated reduction in microvascular complications over time with the possible impacts on life expectancy and risk of complications [20].

The older NEW2D patients had better glycemic control at the baseline compared to patients $<65$ years of age no matter if we use the glycemic target of HbAlc $<7.0 \%$ or a more 
TABLE 1: Characteristics of younger and older groups of newly diagnosed diabetes participants at baseline.

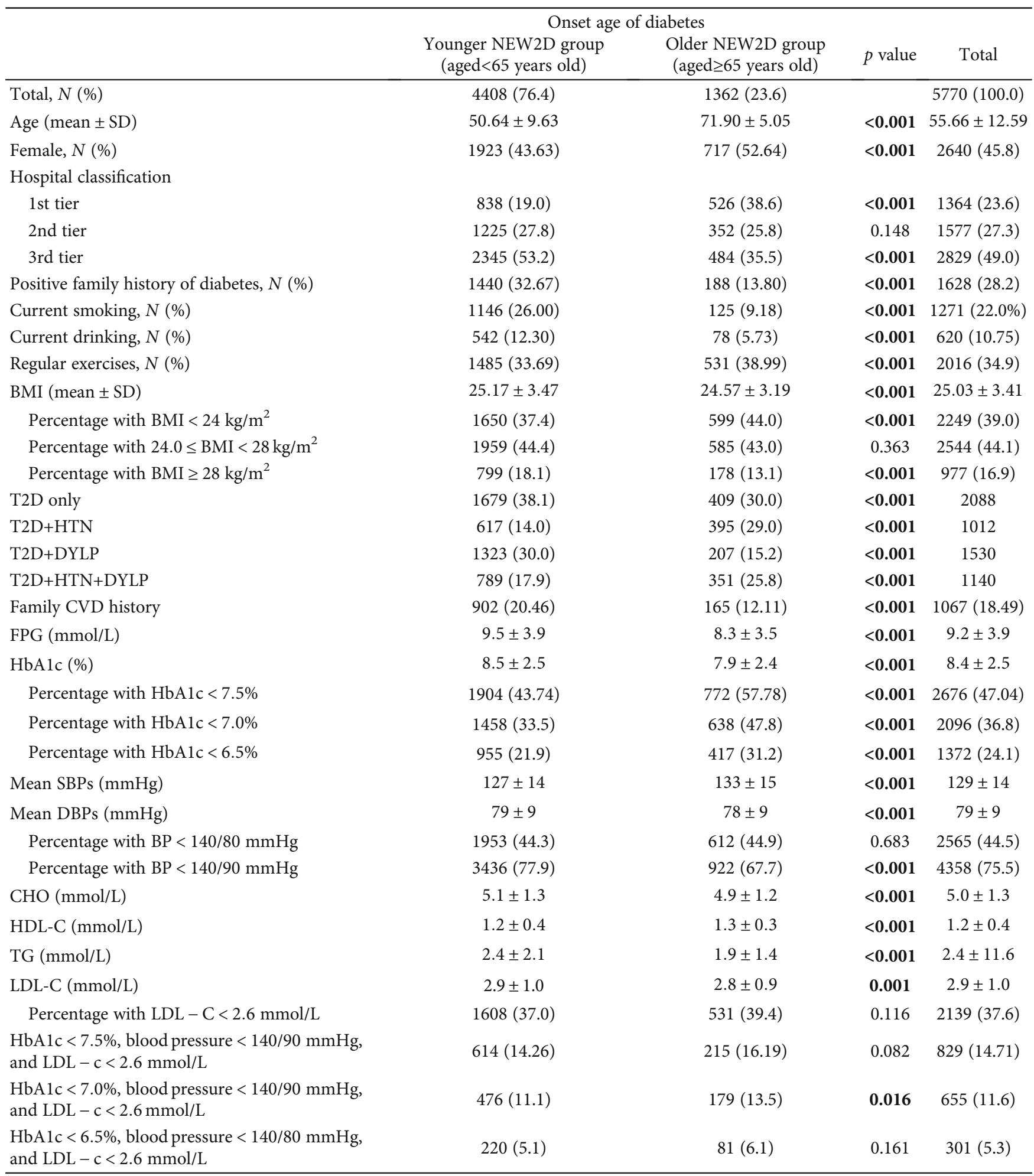

1st tier: community hospitals; 2nd tier: secondary/city level hospitals; 3rd tier: teaching or comprehensive central hospitals (tier 3); BMI: body mass index; SBP: systolic blood pressure; DBP: diastolic blood pressure; CHO: cholesterol; LDL-C: low-density lipoprotein cholesterol; HDL-C: high-density lipoprotein cholesterol; FPG: fasting plasma glucose; T2D: diabetes; HTN: hypertension; DYLP: dyslipidemia.

or less strict target, which was consistent with previous studies $[21,22]$. Presumably, older people had better adherence to the lifestyle program compared with the younger age groups.
Moreover, the older NEW2D mostly resemble mild agerelated diabetes (MARD), who only had modest metabolic derangements $[23,24]$. A real-world population suggested 

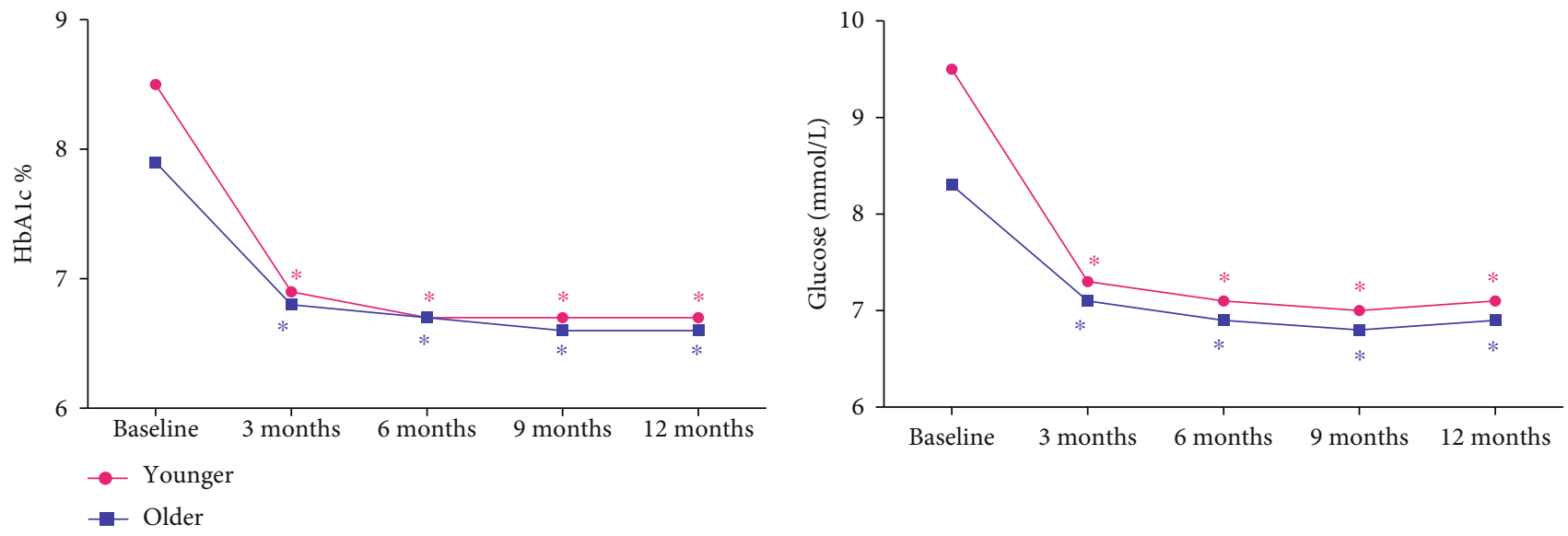

(a)
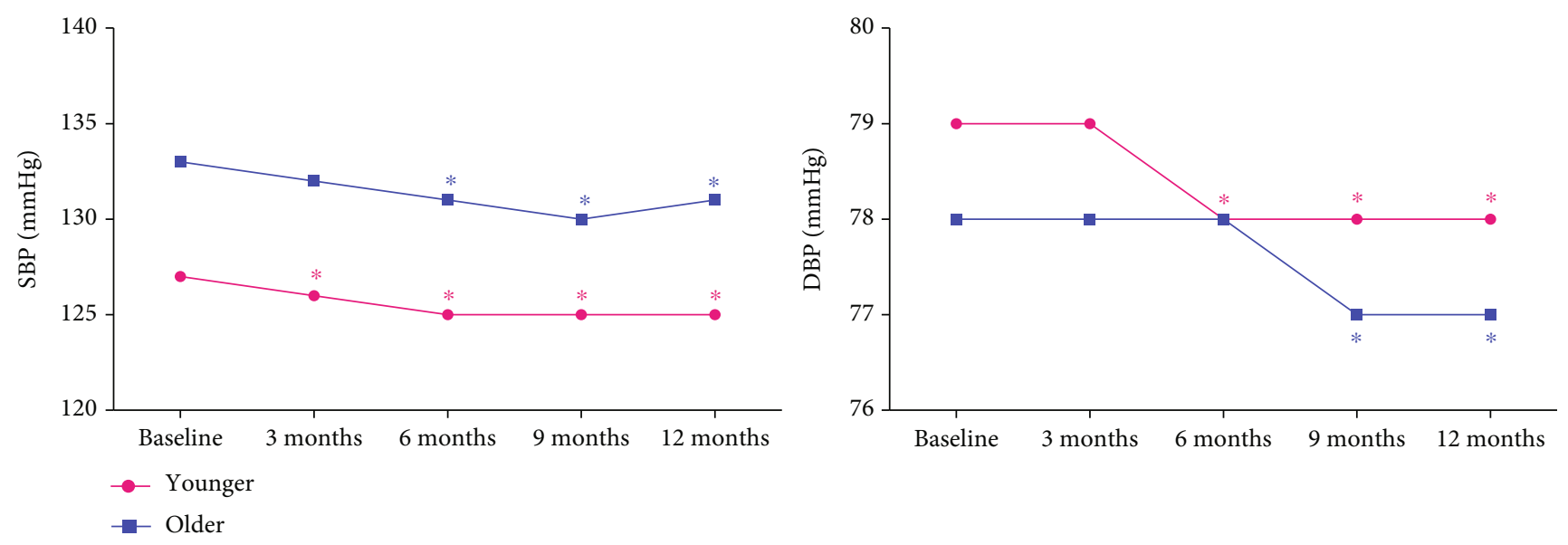

(b)
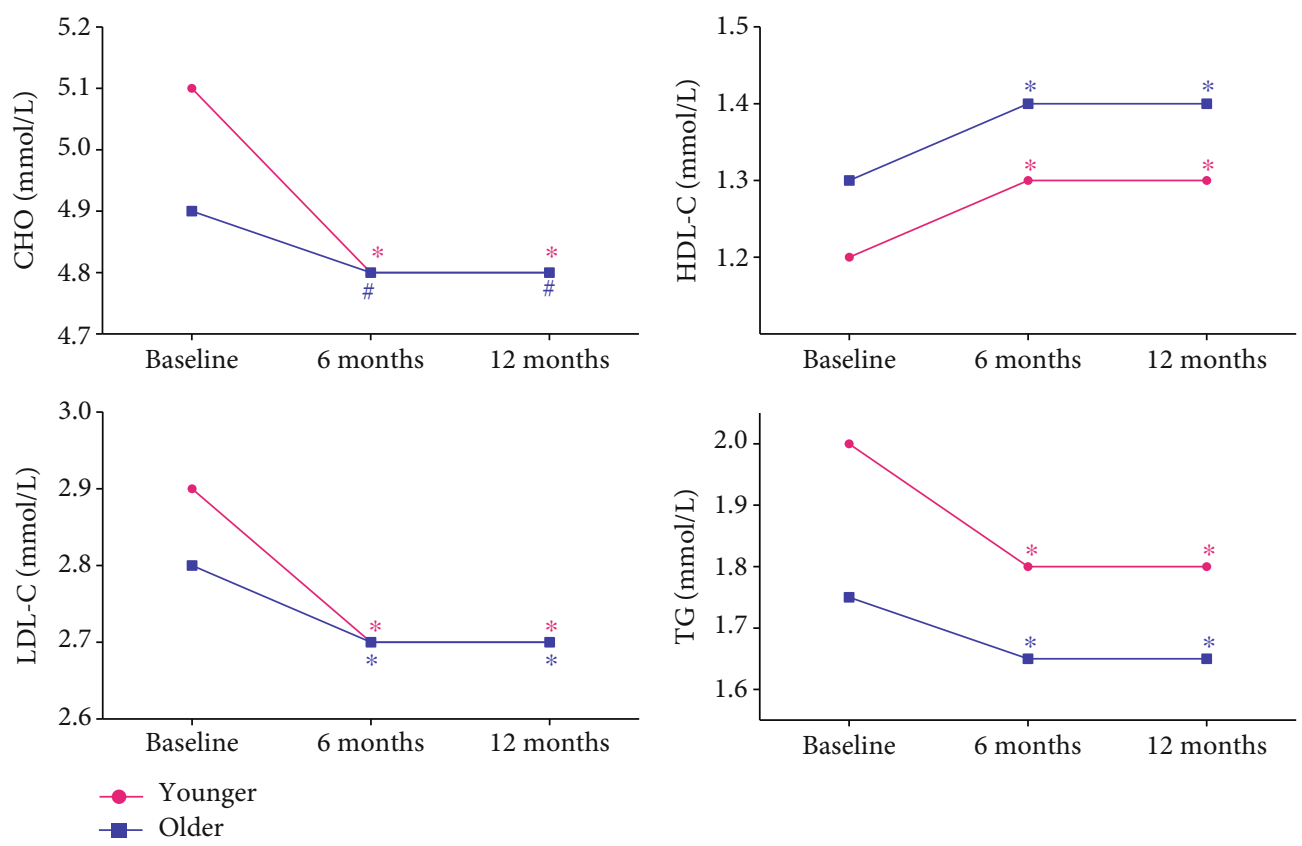

(c)

FIGURE 1: Change of blood glucose, glycosylated hemoglobin (HbA1c), blood pressure (BP), and blood lipid during 12 months follow-up. (a) Change of glycosylated hemoglobin (HbAlc) and blood glucose during follow-up. (b) Change of systolic and diastolic blood pressure during follow-up. (c) Change of blood lipid during follow-up. ${ }^{\#} p<0.05,{ }^{*} p<0.01$ compared to baseline. 


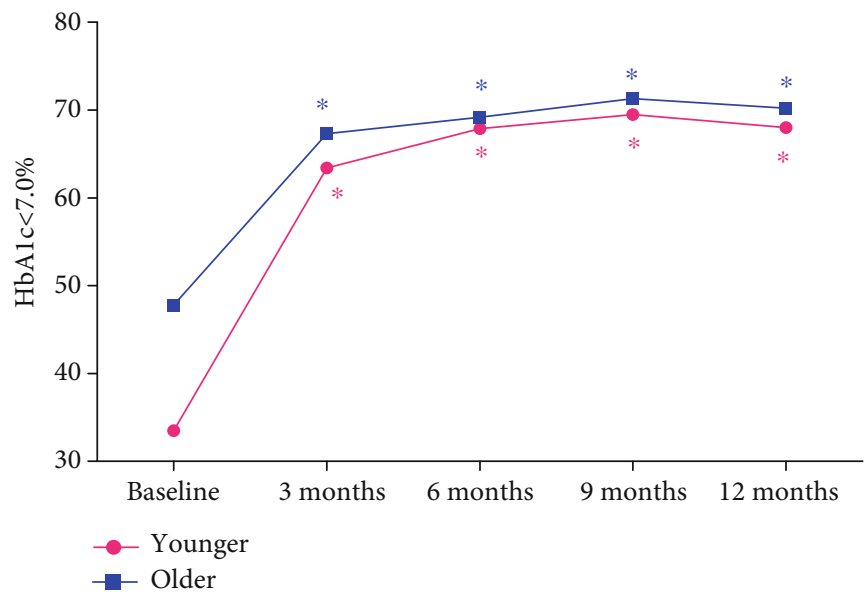

(a)

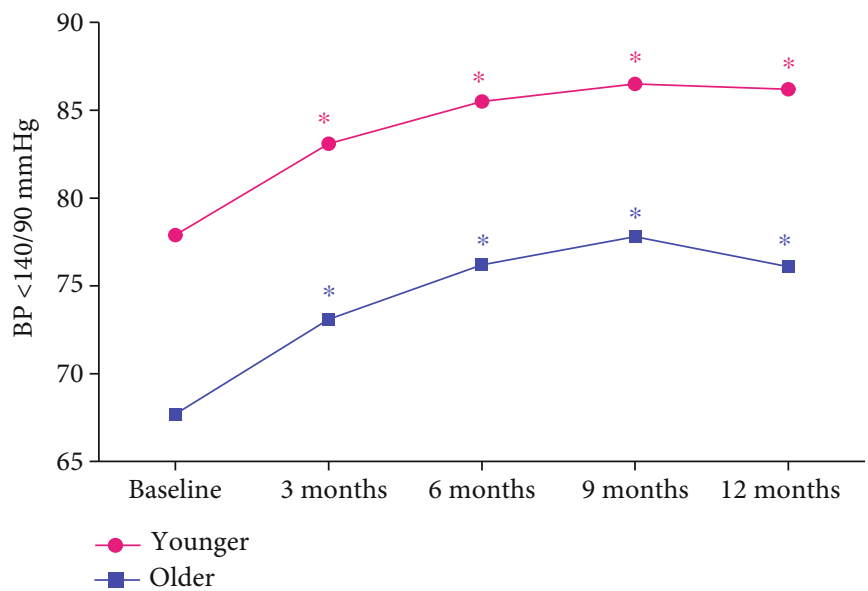

(b)

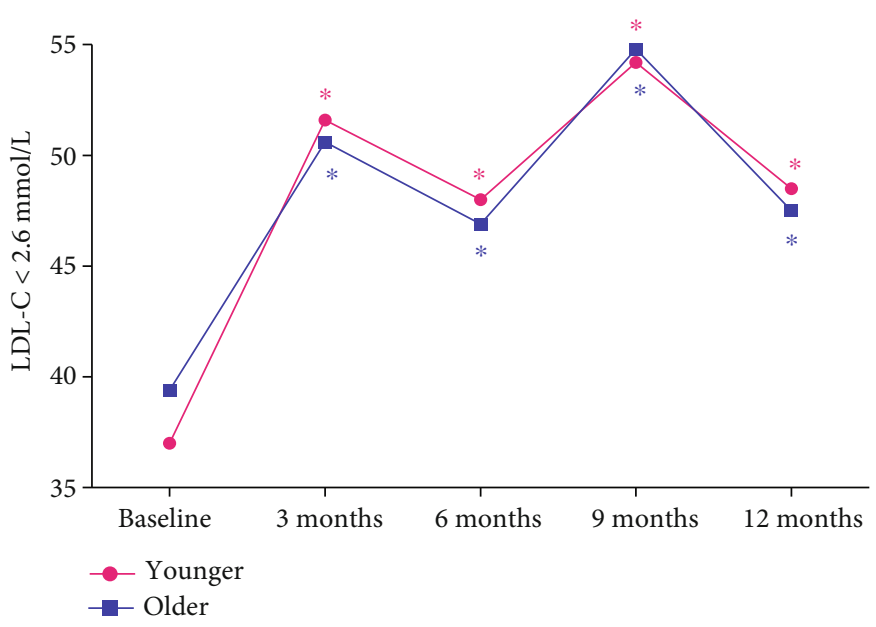

(c)

Figure 2: Continued. 


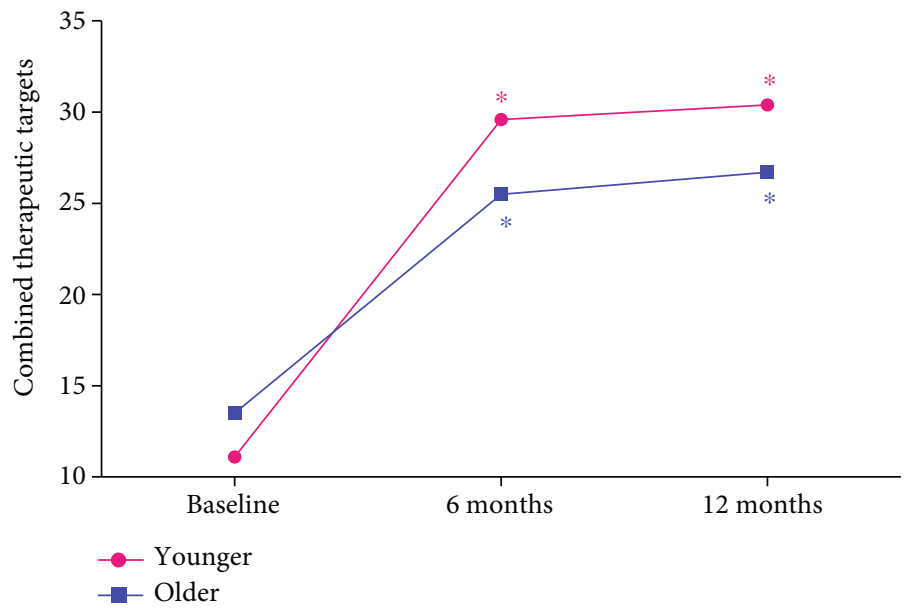

(d)

Figure 2: Proportions of patients achieving therapeutic targets of $\mathrm{HbA} 1 \mathrm{c}<7.0 \%, \mathrm{BP}<140 / 90 \mathrm{mmHg}$, and $\mathrm{LDL}-\mathrm{C}<2.6 \mathrm{mmol} / \mathrm{L}$. (a) Proportions of patients achieving therapeutic targets of HbAlc $<7.0 \%$. (b) Proportions of patients achieving therapeutic targets of $\mathrm{BP}<140 / 90 \mathrm{mmHg}$. (c) Proportions of patients achieving therapeutic targets of $\mathrm{LDL}-\mathrm{C}<2.6 \mathrm{mmol} / \mathrm{L}$. (d) Proportions of patients achieving three combined therapeutic targets. ${ }^{*} p<0.01$ compared to baseline.

the rate of deterioration in those diagnosed at over 70 years of age was very low, with $66 \%$ having a rate of deterioration of less than $1.1 \mathrm{mmol} / \mathrm{mol} \mathrm{HbAlc}$ per year [25]. In addition, older adults ( $>65$ years) with diabetes are at risk of developing a similar spectrum of microvascular complications as their younger counterparts with diabetes, albeit probably at lower absolute risk if they develop their diabetes later in life, which will limit duration. Therefore, treatment in individuals diagnosed older may not need to be as aggressive as those diagnosed younger.

LDL-C reduction was associated with the greatest CVD risk reduction, followed by blood pressure and glycemic control [5]. However, in NEW2D STUDY, only little progress has made with regard to hyperlipidemia management during 12 months follow-up, with just $47.5 \%$ of older NEW2D having their LDL-C levels adequately controlled, and only $18.4 \%$ having statin treatment at 12 months. Recent guidelines suggested that moderate-intensity statin therapy should be started in patients 40 to 75 years of age with diabetes mellitus and $\mathrm{LDL}-\mathrm{C} \geq 1.8 \mathrm{mmol} / \mathrm{L}$ if there is no contraindication without calculating 10-year atherosclerotic cardiovascular disease (ASCVD) risk [26]. This pattern represented a gap from the clinical guidelines and indicated that improvement in the quality of lipid management were needed in patients with T2D in the real world.

There are some limitations of this study. First, given the limitations of observational research and our short follow-up time, the clinical implication of the observed characteristics in the older NEW2D participants was not known. Prospective cohort studies with longer follow-up are necessary to observe the natural history of newly diagnosed diabetes in Chinese older patients. Secondly, the $\mathrm{HbAlc}$ target for older patients was still controversial. However, as this study was an observational cohort study, with the aim to evaluate clinical outcomes and glycemic control in the real world in China, we did not stratify the target of glucose control for different ages in this study. Randomized, prospective trials that have examined glycemic control and complications focusing on the older patient ( $>65$ years) are needed to obtain the optimal glycemic target.

\section{Conclusions}

The older NEW2D patients have special metabolic profiles and higher proportion of comorbid hypertension and hyperlipidemia. The proportion achieving adequate control of risk factors for cardiovascular disease in older NEW2D patients were improved during treatment. However, control of glycemia, BP, and LDL were far from optimal despite the widespread use of guidelines for the management of diabetes and CVD. Awareness and application of published recommendations need to be reinforced.

\section{Data Availability}

The data that support the findings of this study are available from VitalStrategic Research Institute (Shanghai, China) but restrictions apply to the availability of these data, which were used under license for the current study, and so are not publicly available. Data are however available from the authors upon reasonable request and with permission of VitalStrategic Research Institute (Shanghai, China).

\section{Disclosure}

The funding organization had no role in the study design, data collection or analysis, interpretation of the data, and decision to approve publication of the finished manuscript. 


\section{Conflicts of Interest}

Linong Ji has received fees for lecture presentations from AstraZeneca, Merck, Novartis, Lilly, Roche, Sanofi-Aventis, and Takeda. Linong Ji has received consulting fees from companies including AstraZeneca, Merck, Novartis, Lilly, Roche, Sanofi-Aventis, and Takeda. Linong Ji has received grants/research support from AstraZeneca, Bristol-Myers Squibb, Merck, Novartis, and Sanofi-Aventis. There are no other disclosures for other authors.

\section{Authors' Contributions}

Linong Ji, Dayi Hu, and Changyu Pan conceived the idea for the study and designed the study protocol. Linong Ji, Dayi $\mathrm{Hu}$, Changyu Pan, and Xiaoling Cai contributed to data acquisition. Danyi Zhang and Jie Xu performed the statistical analyses; Xiaoling Cai, Fang Lv, and Linong Ji prepared the manuscript outlines and drafts. All authors contributed to the critical revision of manuscript drafts, as well as giving final approval for submitted manuscript content.

\section{Acknowledgments}

The authors of this manuscript would like to thank all CCMR-NEW2D study investigators in the participated hospitals for their contribution to the successful completion of the CCMR-NEW2D study. This work was supported by AstraZeneca (China) company.

\section{References}

[1] D. LeRoith, G. J. Biessels, S. S. Braithwaite et al., "Treatment of diabetes in older adults: an endocrine society* clinical practice guideline," The Journal of Clinical Endocrinology and Metabolism, vol. 104, no. 5, pp. 1520-1574, 2019.

[2] J. E. Shaw, R. A. Sicree, and P. Z. Zimmet, "Global estimates of the prevalence of diabetes for 2010 and 2030," Diabetes Research and Clinical Practice, vol. 87, no. 1, pp. 4-14, 2010.

[3] Y. Xu, L. Wang, J. He et al., "Prevalence and control of diabetes in Chinese adults," JAMA, vol. 310, no. 9, pp. 948-959, 2013.

[4] D. K. Arnett, R. S. Blumenthal, M. A. Albert et al., "2019 ACC/AHA guideline on the primary prevention of cardiovascular disease: a report of the American College of Cardiology/American Heart Association Task Force on Clinical Practice Guidelines," Journal of the American College of Cardiology, vol. 74, no. 10, pp. e177-e232, 2019.

[5] E. Y. F. Wan, C. S. C. Fung, E. Y. T. Yu et al., "Effect of multifactorial treatment targets and relative importance of hemoglobin A1c, blood pressure, and low-density lipoprotein-cholesterol on cardiovascular diseases in Chinese primary care patients with type 2 diabetes mellitus: a population-based retrospective cohort study," Journal of the American Heart Association, vol. 6, no. 8, article e006400, 2017.

[6] K. Wong, D. Glovaci, S. Malik et al., "Comparison of demographic factors and cardiovascular risk factor control among U.S. adults with type 2 diabetes by insulin treatment classification," Journal of Diabetes and its Complications, vol. 26, no. 3, pp. 169-174, 2012.
[7] S. G. Sazlina, I. Mastura, Z. Ahmad et al., "Control of glycemia and other cardiovascular disease risk factors in older adults with type 2 diabetes mellitus: data from the adult diabetes control and management," Geriatrics \& Gerontology International, vol. 14, no. 1, pp. 130-137, 2014.

[8] N. D. Wong, C. Patao, K. Wong, S. Malik, S. S. Franklin, and U. Iloeje, "Trends in control of cardiovascular risk factors among US adults with type 2 diabetes from 1999 to 2010: comparison by prevalent cardiovascular disease status," Diabetes \& Vascular Disease Research, vol. 10, no. 6, pp. 505-513, 2013.

[9] L. Ji, D. Hu, C. Pan et al., "Primacy of the 3B approach to control risk factors for cardiovascular disease in type 2 diabetes patients," The American Journal of Medicine, vol. 126, no. 10, pp. 925.e11-925.e22, 2013.

[10] M. M. Bała, E. Płaczkiewicz-Jankowska, R. Topór-Mądry et al., "Is newly diagnosed type 2 diabetes treated according to the guidelines? Results of the Polish ARETAEUS1 study," Polskie Archiwum Medycyny Wewnętrznej, vol. 121, no. 1-2, pp. 7-17, 2011.

[11] X. Huo, L. Gao, L. Guo et al., "Risk of non-fatal cardiovascular diseases in early-onset versus late-onset type 2 diabetes in China: a cross-sectional study," The Lancet Diabetes and Endocrinology, vol. 4, no. 2, pp. 115-124, 2016.

[12] X. Zou, X. Zhou, L. Ji et al., "The characteristics of newly diagnosed adult early-onset diabetes: a population-based crosssectional study," Scientific Reports, vol. 7, no. 1, article 46534, 2017.

[13] X. Cai, D. Hu, C. Pan et al., "The risk factors of glycemic control, blood pressure control, lipid control in Chinese patients with newly diagnosed type 2 diabetes A nationwide prospective cohort study," Scientific Reports, vol. 9, no. 1, p. 7709, 2019.

[14] X. Cai, D. Hu, C. Pan et al., "Evaluation of effectiveness of treatment paradigm for newly diagnosed type 2 diabetes patients in Chin: A nationwide prospective cohort study," Journal of Diabetes Investigation, 2019.

[15] A. Rawshani, A. Rawshani, S. Franzén et al., "Risk factors, mortality, and cardiovascular outcomes in patients with type 2 diabetes," The New England Journal of Medicine, vol. 379, no. 7, pp. 633-644, 2018.

[16] E. S. Huang, J. Y. Liu, and H. H. Moffet, "Glycemic control, complications, and death in older diabetic patients: the diabetes and aging study," Diabetes Care, vol. 34, no. 6, pp. 13291336, 2011.

[17] S. Greenfield, J. Billimek, F. Pellegrini et al., "Comorbidity affects the relationship between glycemic control and cardiovascular outcomes in Diabetes," Annals of Internal Medicine, vol. 151, no. 12, pp. 854-860, 2009.

[18] Action to Control Cardiovascular Risk in Diabetes Study Group, H. C. Gerstein, and M. E. Miller, "Effects of intensive glucose lowering in type 2 diabetes," The New England Journal of Medicine, vol. 358, no. 24, pp. 2545-2559, 2008.

[19] A. Forbes, T. Murrells, H. Mulnier, and A. J. Sinclair, "Mean $\mathrm{HbA}_{1 \mathrm{c}}, \mathrm{HbA}_{1 \mathrm{c}}$ variability, and mortality in people with diabetes aged 70 years and older: a retrospective cohort study," The Lancet Diabetes and Endocrinology, vol. 6, no. 6, pp. 476-486, 2018.

[20] F. Ismail-Beigi, E. Moghissi, M. Tiktin, I. B. Hirsch, S. E. Inzucchi, and S. Genuth, "Individualizing glycemic targets in type 2 diabetes mellitus: implications of recent clinical 
trials," Annals of Internal Medicine, vol. 154, no. 8, pp. 554559, 2011.

[21] B. M. Egan, J. Li, T. E. Wolfman, and A. Sinopoli, "Diabetes and age-related demographic differences in risk factor control," Journal of the American Society of Hypertension, vol. 8, no. 6, pp. 394-404, 2014.

[22] S. A. Berkowitz, J. B. Meigs, and D. J. Wexler, “Age at type 2 diabetes onset and glycaemic control: results from the National Health and Nutrition Examination Survey (NHANES) 2005-2010," Diabetologia, vol. 56, no. 12, pp. 2593-2600, 2013.

[23] E. Ahlqvist, P. Storm, A. Käräjämäki et al., "Novel subgroups of adult-onset diabetes and their association with outcomes: a data-driven cluster analysis of six variables," The Lancet Diabetes and Endocrinology, vol. 6, no. 5, pp. 361-369, 2018.

[24] J. M. Dennis, B. M. Shields, W. E. Henley, A. G. Jones, and A. T. Hattersley, "Disease progression and treatment response in data-driven subgroups of type 2 diabetes compared with models based on simple clinical features: an analysis using clinical trial data," The Lancet Diabetes and Endocrinology, vol. 7, no. 6, pp. 442-451, 2019.

[25] L. A. Donnelly, K. Zhou, A. S. F. Doney, C. Jennison, P. W. Franks, and E. R. Pearson, "Rates of glycaemic deterioration in a real-world population with type 2 diabetes," Diabetologia, vol. 61, no. 3, pp. 607-615, 2018.

[26] S. M. Grundy, N. J. Stone, A. L. Bailey et al., "2018 AHA/ACC/AACVPR/AAPA/ABC/ACPM/ADA/AGS/APhA/ASPC /NLA/PCNA guideline on the management of blood cholesterol: a report of the American College of Cardiology/American Heart Association Task Force on Clinical Practice Guidelines," Circulation, vol. 139, no. 25, pp. e1082-e1143, 2019. 


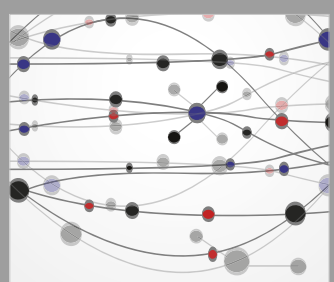

The Scientific World Journal
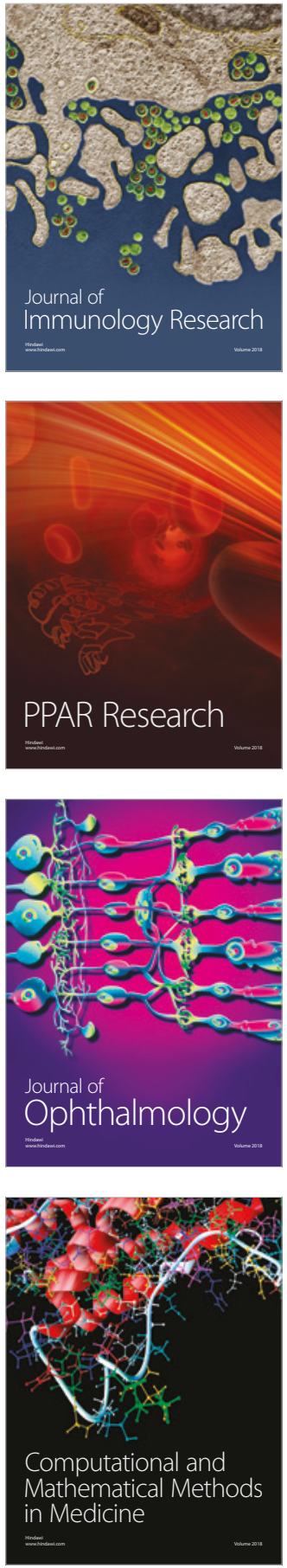

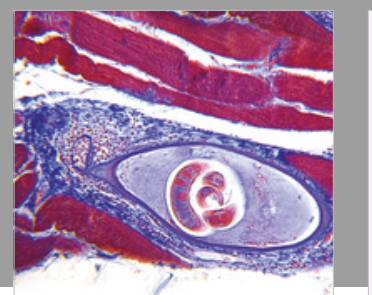

Gastroenterology Research and Practice

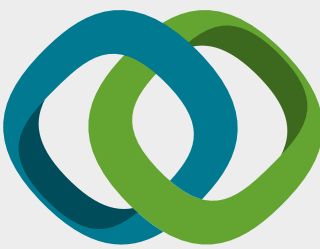

\section{Hindawi}

Submit your manuscripts at

www.hindawi.com
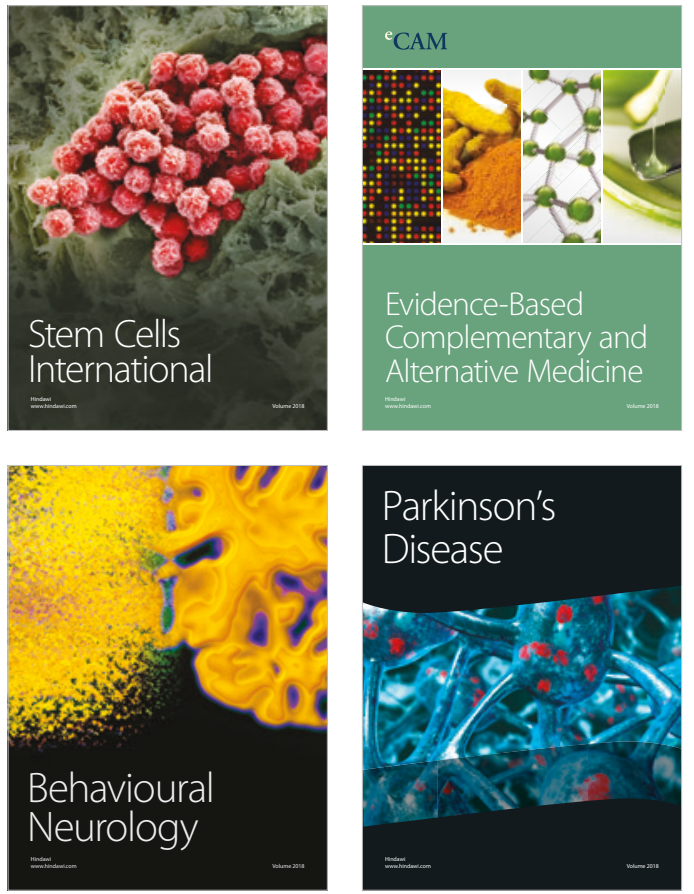

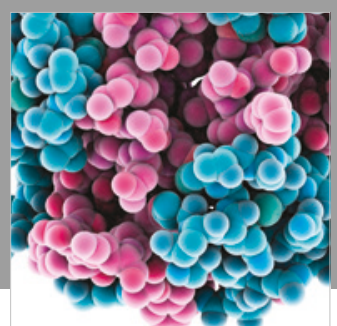

ournal of

Diabetes Research

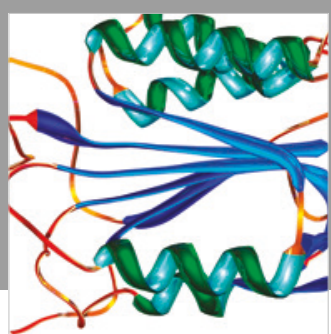

Disease Markers
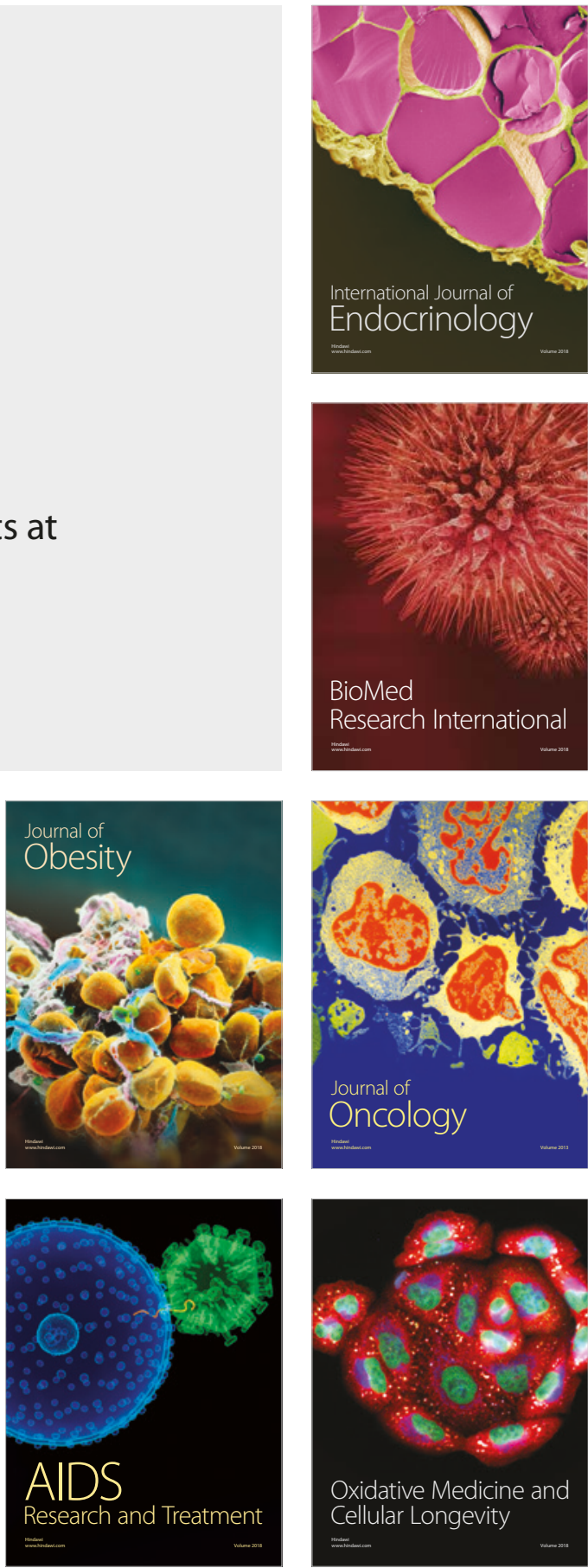